\title{
Evaluation of the Microbact-24E bacterial identification system
}

\author{
JULIA M LING, Y-W HUI, G L FRENCH Department of Microbiology, The Chinese University of \\ Hong Kong, The Prince of Wales Hospital, Shatin, New Territories, Hong Kong
}

SUMMARY The Microbact 24E (MB24E) system is a commercial microsystem for the identification of common clinical isolates of Enterobacteriaceae and non-fermenting Gram negative bacilli, and consists of dehydrated substrates distributed in the wells of microtitre trays. This system was compared with the API20E for the identification of 386 bacterial isolates, which included 284 clinical and 102 environmental organisms. There was $97 \%$ and $91 \%$ agreement for the identification of clinical isolates of Enterobacteriaceae and other Gram negative bacilli, respectively. The identification of environmental isolates by both systems was less satisfactory.

The API20E has a more extensive database than the MB24E and is thus more reliable for the identification of rare or unusual organisms, but the MB24E is cheaper, is easy and convenient to use, and is suitable for a routine microbiology laboratory.

The Microbact 24E (MB24E) (Microbact Systems, Disposable Products, Adelaide, South Australia) is a commercial identification system for enterobacteria and other Gram negative bacteria. It consists of dehydrated substrates for 24 different biochemical tests placed in the wells of a microtitre tray. Four organisms can be tested in each 96 well tray. A saline suspension of the test organism is added to each of the 24 wells and appropriate wells are overlaid with sterile paraffin oil. After overnight incubation at $37^{\circ} \mathrm{C}$ suitable reagents are added and colour changes of the different tests are recorded. The results are transcribed into a code and organisms are identified by use of a computer based profile register.

Many other commercial kits for the identification of Gram negative bacteria are available, ${ }^{1-6}$ and the API20E system has been available for more than 10 years, has gained international acceptance, and has been used as a reference against which newer systems are often compared. Like the API20E, the MB24E system is designed for the identification of enterobacteria $^{7}$ as well as non-fermenters. We compared the performance of the API20E and MB24E systems for the identification of these organisms in a clinical laboratory.

\section{Material and methods}

A total of 386 bacterial strains were examined: 284

Accepted for publication 3 March 1988 were recent clinical isolates (mainly from blood cultures) and 102 were environmental isolates from Hong Kong rivers. Two hundred and sixty nine strains belonged to the family Enterobacteriaceae and 117 were miscellaneous Gram negative bacteria. Five reference strains were also tested: Escherichia coli ATCC 25922 and NCTC 10418; Pseudomonas aeruginosa ATCC 27853 and NCTC 10662, and Salmonella typhimurium 42R500. All isolates were stored on nutrient agar slopes at room temperature before testing.

Two commercial microidentification kits were used, the Microbact-24E (MB24E, Microbact Systems, Disposable Products, South Australia) and the API20E (API Systems, SA, Vercieu, France). Twenty four and 20 biochemical tests are provided by the two systems, respectively (table 1 ): 18 tests are common to both systems. Tests for acid from xylose, lactose, adonitol, raffinose and salicin, and for malonate are provided only by the MB24E system, and tests for acid from meliobiose and amygdalin are provided only by the API20E system.

Bacterial isolates were subcultured on to MacConkey or nutrient agar (Oxoid, Basingstoke, England) to check for purity. The inoculum was prepared by picking one or two well isolated colonies and emulsifying in $3 \mathrm{ml}$ saline (MB24E) or $5 \mathrm{ml}$ distilled water (API20E). The systems were inoculated according to the manufacturer's instructions and incubated at $37^{\circ} \mathrm{C}$ for $\mathbf{2 4}$ hours for enterobacteria and for $\mathbf{4 8}$ hours for other Gram negative bacteria. 
Table 1 Biochemical tests available on MB24E and API20E identification systems for Gram negative bacteria

\begin{tabular}{|c|c|c|c|}
\hline \multicolumn{2}{|l|}{$M B 24 E$} & \multicolumn{2}{|l|}{$A P I 20 E$} \\
\hline$\overline{T e s t}$ & Abbreviation & $\overline{T e s t}$ & Abbreviation \\
\hline $\begin{array}{l}\text { Lysine decarboxylase } \\
\text { Ornithine decarboxylase } \\
\text { Hydrogen sulphide production } \\
\text { Acid from glucose } \\
\text { Acid from mannitol } \\
\text { Acid from xylose } \\
\text { ß-Galactosidase } \\
\text { Indole production } \\
\text { Urea hydrolysis } \\
\text { Voges-Proskauer reaction } \\
\text { Citrate utilisation } \\
\text { Tryptophan deaminase } \\
\text { Gelatin liquefaction } \\
\text { Malonate utilisation } \\
\text { Acid from: } \\
\text { Inositol } \\
\text { Sorbitol } \\
\text { Rhamnose } \\
\text { Sucrose } \\
\text { Lactose } \\
\text { Arabinose } \\
\text { Adonitol } \\
\text { Raffinose } \\
\text { Salicin } \\
\text { Arginine dihydrolase }\end{array}$ & $\begin{array}{l}\text { LYS } \\
\text { ORN } \\
\text { HeS } \\
\text { GLU } \\
\text { MAN } \\
\text { XYL } \\
\text { ONPG } \\
\text { IND } \\
\text { URE } \\
\text { VP } \\
\text { CIT } \\
\text { TDA } \\
\text { GEL } \\
\text { MAL } \\
\text { INO } \\
\text { SOR } \\
\text { RHA } \\
\text { SUC } \\
\text { LAC } \\
\text { ARA } \\
\text { ADO } \\
\text { RAF } \\
\text { SAL } \\
\text { ARG }\end{array}$ & $\begin{array}{l}\text { ß-Galactosidase } \\
\text { Arginine dihydrolase } \\
\text { Lysine decarboxylase } \\
\text { Ornithine decarboxylase } \\
\text { Citrate utilisation } \\
\text { Hydrogen sulphide production } \\
\text { Urea hydrolysis } \\
\text { Tryptophan deaminase } \\
\text { Indole production } \\
\text { Voges-Proskauer reaction } \\
\text { Gelatin liquefaction } \\
\text { Acid from: } \\
\text { Glucose } \\
\text { Mannitol } \\
\text { Inositol } \\
\text { Sorbitol } \\
\text { Rhamnose } \\
\text { Sucrose } \\
\text { Meliobiose } \\
\text { Amygdalin } \\
\text { Arabinose }\end{array}$ & $\begin{array}{l}\text { ONPG } \\
\text { ADH } \\
\text { LDC } \\
\text { ODC } \\
\text { CIT } \\
\text { H2S } \\
\text { URE } \\
\text { TDA } \\
\text { IND } \\
\text { VP } \\
\text { GEL } \\
\text { GLU } \\
\text { MAN } \\
\text { INO } \\
\text { SOR } \\
\text { RHA } \\
\text { SAC } \\
\text { MEL } \\
\text { AMY } \\
\text { ARA }\end{array}$ \\
\hline
\end{tabular}

The systems were observed for colour change with or without the addition of suitable reagents according to the manufacturers' instructions. In both systems identifications are made by the construction of an appropriate numerical code. Each biochemical test is given a numerical value, awarded only to a positive reaction. These values are converted into a code number which identifies the organism by the appropriate profile register. A single bacterial species may have several valid code numbers because of natural variations in biochemical reactions. In this study it was assumed that the API20E system gave "correct" identities, and that when there were discrepancies between the two systems the MB24E was in error.

\section{Results}

Table 2 shows the proportion of identifications for which the two systems were in agreement. The percen- tage of agreement for clinical isolates of enterobacteria was high, with $96.9 \%$ to genus level and $94.3 \%$ to species level. There was less agreement between the two systems for the identification of environmental isolates, being $80.5 \%$ and $76.6 \%$ to the genus and species levels, respectively. For all enterobacteria $92.2 \%$ of identities agreed at the genus level and $89.2 \%$ at the species level.

Most of the common clinical species gave similar identities with the two systems. Most discrepancies occurred with Enterobacter sp and a few with Klebsiella sp, Citrobacter sp and Serratia sp (tables 3 and 4). Salmonella sp were correctly identified by MB24E except for one isolate which was misidentified as Shigella boydii because of inert sugar reactions. The MB24E system had recommended that the Shigella identification be confirmed by serotyping, and this organism would also have been identified correctly if the property of motility had been taken into account. One isolate of $S$ choleraesuis, whose identity was

Table 2 Rates of agreement between both systems

\begin{tabular}{|c|c|c|c|}
\hline & \multicolumn{2}{|l|}{ Strains } & \multirow[b]{2}{*}{ Total $(N o(\%))$} \\
\hline & Clinical & Environmental & \\
\hline $\begin{array}{l}\text { Enterobacteriaceae } \\
\text { Agreement to species level } \\
\text { genus level } \\
\text { Miscellaneous Gram negative } \\
\text { Agreement to species level } \\
\text { genus level }\end{array}$ & $\begin{array}{l}192 \\
181(94 \cdot 3) \\
186(96 \cdot 9) \\
92 \\
74(80 \cdot 4) \\
84(91 \cdot 3)\end{array}$ & $\begin{array}{l}77 \\
59(76 \cdot 6) \\
62(80 \cdot 5) \\
25 \\
22(88 \cdot 0) \\
22(88 \cdot 0)\end{array}$ & $\begin{array}{l}269 \\
240(89 \cdot 2) \\
248(92 \cdot 2) \\
117 \\
96(82 \cdot 1) \\
106(90 \cdot 6)\end{array}$ \\
\hline
\end{tabular}


Table 3 Comparison of both systems for identification of clinical and environmental isolates

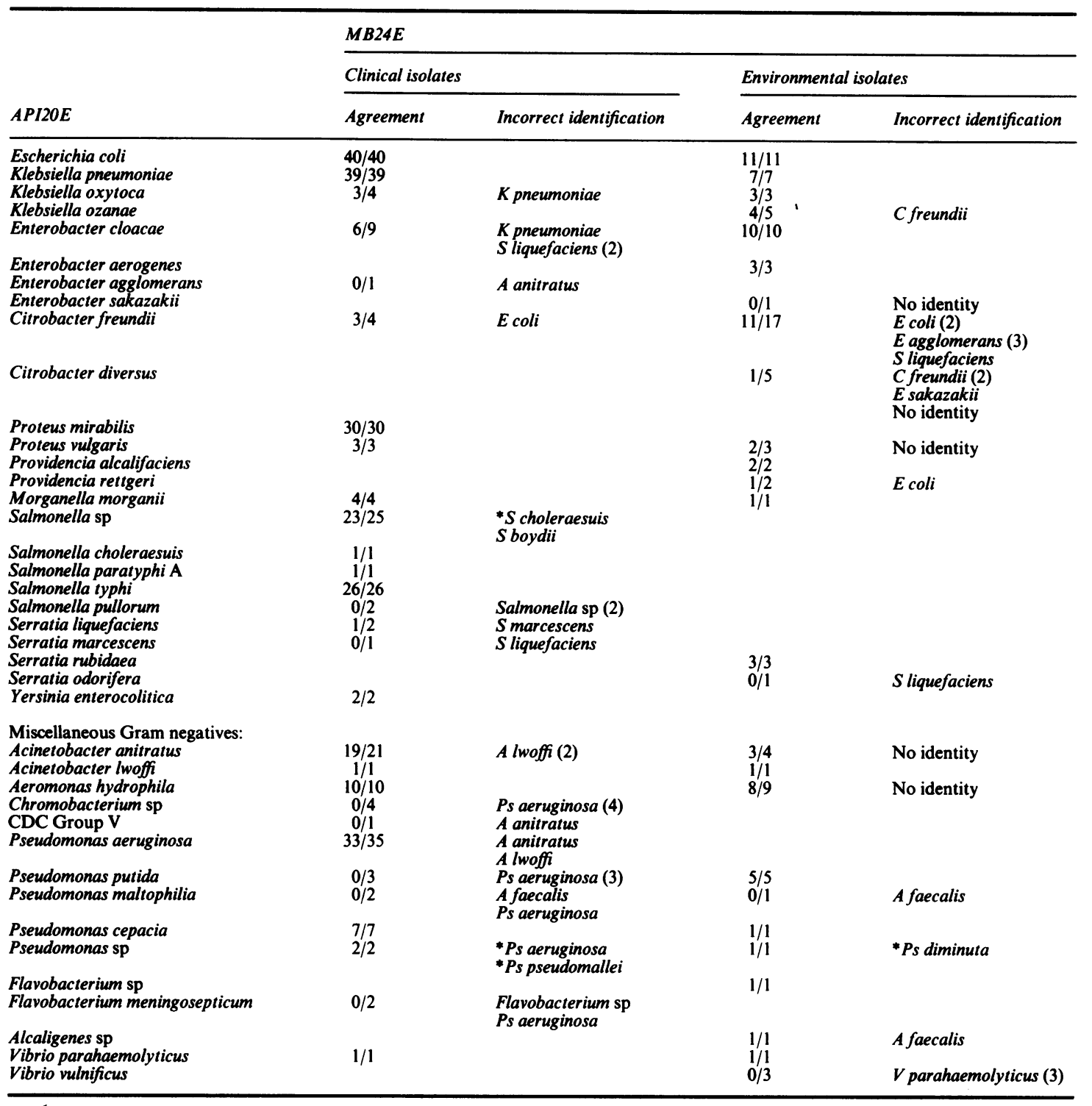

*speciated bythe MB24E system.

proved by serotyping, was correctly identified to species level by MB24E but only to genus level by API20E.

Of the environmental isolates, one strain each of Enterobacter sakazakii, Citrobacter diversus, and Proteus vulgaris could not be identified by MB24E (table 3). Some isolates of Klebsiella sp, Citrobacter sp, and Providencia sp were misidentified because of discrepant biochemical reactions (table 4).

Among the miscellaneous Gram negative bacteria, there was $91.3 \%$ agreement to genus level, and $80.4 \%$ to species level for clinical isolates, and $88 \%$ agreement to both genus and species levels for environmental isolates (table 2). Thus for these organisms there was an overall agreement between the two systems of $90.6 \%$ to genus level and $82 \cdot 1 \%$ to species level.

Misidentified clinical isolates of miscellaneous Gram negative bacteria included Acinetobacter sp and Pseudomonas sp (tables 3 and 4). Unlike API20E, the 
Table 4 Misidentification by MB24E system of clinical and environmental isolates and discrepant reactions compared with those of API20E system

\begin{tabular}{|c|c|c|c|}
\hline$A P I 20 E$ & $\begin{array}{l}\text { No of } \\
\text { isolates }\end{array}$ & $M B 24 E$ & $\begin{array}{l}\text { Discrepant hiochemical } \\
\text { results of } M B 24 E^{*}\end{array}$ \\
\hline \multicolumn{4}{|l|}{ Enterobacteriaceae: } \\
\hline Klebsiella oxvtoca & 1 & K pneumonicie & IND - \\
\hline Klebsiella ozanae (e) & 1 & C freundii & ADO - RAF - \\
\hline Enterohacter cloacae & 1 & K pneumoniae & LYS + ORN - ARG - \\
\hline \multirow{4}{*}{$\begin{array}{l}\text { Enterohacter agglomerans } \\
\text { Citrobacter freundii } \\
\text { Citrobacter freundii (e) }\end{array}$} & $\hat{1}$ & $A$ anitratus & LYS + GEL - Sugars - \\
\hline & $3(1, \mathrm{e})$ & Ecoli & LYS + CIT - \\
\hline & 1 & E agglomerans & CIT - ARG - \\
\hline & i & Sliquefaciens & $\mathrm{SUC}+\mathrm{RAF}+\mathrm{ARG}-$ \\
\hline \multirow[t]{2}{*}{$C$ diversus (e) } & i & Cfreundii & MAL - ADO - SAL - \\
\hline & $i$ & Esakazakii & SOR - SUC + ADO - RAF - \\
\hline Salmonella sp & i & Shoydii & LYS - sugars - \\
\hline Serratia liquefaciens & $i$ & $S$ marcescens & $\mathrm{VP}+\mathrm{RHA}-\mathrm{ARA}-$ \\
\hline Serratia marcescens & i & S liquefaciens & $\mathrm{VP}-\mathrm{RHA}+\mathrm{ARA}+$ \\
\hline Providencia rettgeri (e) & $i$ & Ecoli & $\begin{array}{l}\mathrm{LYS}+\mathrm{ORN}+\mathrm{URE}-\mathrm{CIT}-\mathrm{TDA}- \\
\mathrm{INO} \text { - SOR + ARA + }\end{array}$ \\
\hline \multicolumn{4}{|l|}{ Miscellaneous Gram negatives: } \\
\hline Acinetohacter anitratus & 1 & A lwoffi & GLU - INO - ARA - RAF - \\
\hline & 1 & A lwoffi & $X L Y-I N O$ - ARA - RAF - \\
\hline \multirow[t]{2}{*}{ Pseudomonas aeruginosa } & 1 & A anitratus & OXI - MOT - NIT - ARG - XLY - \\
\hline & 1 & A lwoffi & OXI - MOT - NIT - ARG - XLY - \\
\hline \multirow{4}{*}{$\begin{array}{l}\text { Pseudomonas putida } \\
\text { Pseudomonas maltophilia }\end{array}$} & 3 & Ps aeruginosa & NIT + URE + \\
\hline & 1 & A faecalis & $\mathrm{OXI}+\mathrm{LYS}-$ \\
\hline & I(e) & Afaecalis & CIT - GEL - MAL - \\
\hline & 1 & Ps aeruginosa & $\mathrm{OXI}+\mathrm{GLU}+\mathrm{URE}+\mathrm{ARG}+$ \\
\hline Flavohacterium meningosepticum & 1 & Ps aeruginosa & $\mathrm{MOT}+\mathrm{NIT}+\mathrm{LYS}+\mathrm{MAL}+\mathrm{ARG}+$ \\
\hline
\end{tabular}

$\mathrm{e}=$ Environmental isolate.

MB24E system cannot speciate members of the genus Flavobacterium, and one Fmeningosepticum strain was incorrectly identified as Ps aeruginosa (table 4).

Chromobacterium sp was not available in the database of MB24E so that isolates of this species were identified as Ps aeruginosa. In contrast, two strains of Pseudomonas sp, which were identified only to the genus level by API20E, were correctly identified to the species level by MB24E as $P s$ aeruginosa and Ps pseudomallei.

For the environmental isolates, one strain each of $A$ anitratus and Aeromonas hydrophila could not be identified by MB24E, and one Ps maltophilia strain was misidentified as Alcaligenes faecalis (tables 3 and 4). Vibrio vulnificus was not included in the database of MB24E and this organism was identified as $V$ parahaemolyticus by this system.

The percentage of species isolates positive for some biochemical tests differed between the two systems. For the Enterobacteriaceae, most discrepancies occurred in the tests for urease production and the Voges-Proskauer reaction, for which there was a higher percentage of positive reactions by MB24E. For the miscellaneous Gram negative bacteria, the greatest discrepancies between the two systems were in the tests for the detection of lysine decarboxylase, citrate utilisation, and the production of acid from glucose. Other tests for which there were discrepancies included arabinose assimilation, the Voges-Proskauer reaction, gelatin liquefaction and rhamnose fermentation.

\section{Discussion}

Mugg and Hill, who developed the MB24E system, compared it with the API20E system for the identification of 352 Enterobacteriacae.? Where disagreements were found between the two systems they retested their organisms by their conventional methods, and in all cases the MB24E identifications were found to be "correct". Thus in their hands, the MB24E gave $100 \%$ correct identification, while the API20E was "correct" to species level in $97.4 \%$ of cases. We adopted a different approach in our study. Since conventional tests often give variable results between laboratories, and reactions also depend on the methods used, it is difficult to define a "correct" result. Commercial test systems have fixed procedures and are quality controlled during manufacture. Therefore, if they are used properly they should give consistent and reproducible results. As the API20E is well established and widely accepted we used this as the standard for assessment of the MB24E, while recognising that no test system will give a "correct" answer for every organism. In the present study the MB24E and API20E systems gave very similar identifications to species level for clinical isolates of enterobacteria and miscellaneous Gram negative bacteria. There was less agreement between the two systems for the identification of environmental isolates, but this might be expected as both systems were designed primarily for use in clinical laboratories.

Most of the enterobacteria that were misidentified by the MB24E system were opportunistic pathogens 
such as Enterobacter, Klebsiella, Citrobacter and Serratia. Serratia sp are easily confused with Enterobacter sp, from which they can be differentiated by tests for the production of enzymes such as DNAase, lipase, lecithinase, chitinase and esterase. ${ }^{8}$ Tests for these enzymes are not provided in the MB24E or API20E systems, but these kits recommend that such additional tests be performed if necessary. There were insufficient examples of $E$ agglomerans, $K$ ozanae, $C$ diversus and $P$ rettgeri examined to determine the capacity of MB24E to identify these organisms.

Among the miscellaneous Gram negative bacteria, $A$ hydrophila, Ps aeruginosa, and Ps cepacia were satisfactorily identified by MB24E, but the ability of MB24E to identify other less common non-fermenters could not be assessed. The MB24E includes in its database only two of the halophilic vibrios-namely, $V$ parahaemolyticus and $V$ alginolyticus. $V$ vulnificus was correctly identified by MB24E as $V$ parahaemolyticus but can be differentiated by positive lactose, ONPG, and salicin reactions. Similarly, the MB24E system did not speciate Flavobacterium. In general, the API20E system seemed to have a more extensive database, and problems arose only with relatively uncommon organisms.

The same organisms often gave different biochemical profiles with the two systems, and thus identities must be made from the appropriate profile register rather than from general texts. In some instances rare or unusual organisms are not included in the databases, and these organisms may then be misidentified. For the interpretation of unusual or aberrant results and the identification of rare organisms the skill of an experienced microbiologist is still required.

Experience is also required in reading the colour reactions of these kits. It is important to note that too heavy an inoculum can give inaccurate results; one or two isolated colonies are sufficient for preparation of the inoculation suspension. The lysine decarboxylase reaction of the MB24E system is difficult to read, especially for weakly positive organisms. This is also true for the lysine and ornithine decarboxylase and arginine dihydrolase reactions in the API20E system. A very light orange colour in these three tests should be regarded as negative. The Voges-Proskauer reaction of the API20E system is very slow, requiring at least 10 to 15 minutes to develop ${ }^{79}$-This reaction is slightly faster in the MB24E system, requiring less than 10 minutes. The citrate utilisation test in the API20E system is different to interpret when the reaction is weakly positive. Although a turquoise colour is regarded as positive, the colour varies between very pale greenish-blue and turquoise. This reaction is easier to read in the MB24E system. On the other hand, detection of urease by the MB24E is difficult if a very pale pinkish colour is produced. For other tests, the colour changes in the MB24E are relatively easy to interpret, although the observer must be familiar with weak colour changes and be consistent in scoring. Weak colour changes should be regarded as negative reactions (A Hill, personal communication).

The MB24E system is much easier to inoculate and manipulate than the API20E system, which requires a separate lid and the addition of water to the incubation tray. The API20E is available only as separate strips for individual organisms; the MB24E is packaged either as trays for four organisms or as individual strips. The MB24E is also cheaper. The exact cost will depend on tenders for volume purchases, but at the time of writing, the cost at the Prince of Wales hospital for testing one organism was HK\$19.80 ( $£ 1.46)$ for API20E and HK\$13.43 (£0.4?)for MB24E.

In conclusion, the MB24E gave very similar results to the API20E for the identification of common clinical isolates of both Enterobacteriaceae and nonfermenting Gram negative bacilli, and is suitable for use in a routine diagnostic laboratory. The API20E database is more extensive than that of the MB24E and contains more examples of rare organisms. Both systems are more reliable for the identification of clinical rather than environmental isolates.

\section{References}

1 Blazevic DJ, Mackay DL, Warwood NM. Comparison of MicroID and API20E systems for identification of Enterobacteriaceae. J Clin Microbiol 1979;9:605-8.

2 Appaulbaum PC, Leathers DJ. Evaluation of the Rapid NFT system for identification of Gram-negative, nonfermenting rods. J Clin Microbiol 1984;20:730-4.

3 Castillo CB, Bruckner DA. Comparative evaluation of the Eiken and API20E systems and conventional methods for identification of members of the family Enterobacteriaceae. J. Clin Microbiol 1984;20:754-7.

4 Costigan WJ, Hollick GE. Use of the Autobac IDX system for rapid identification of Enterobacteriaceae and nonfermentative Gram-negative bacilli. J Clin Microbiol 1984;19:301-2.

5 Hayek LJ, Willis GW. Identification of the Enterobacteriaceae: a comparison of the Enterotube II with the API20E.J Clin Pathol 1984;37:344-7.

6 Izard D, Husson MO, Vincent P, Leclerc H, Monget D, Boeufgras JM. Evaluation of the four-hour Rapid 20E system for identification of members of the family Enterobacteriaceae. J Clin Microbiol 1984;20:51-4.

7 Mugg P, Hill A. Comparison of the Microbact-12E and 24E systems and the API-20E system for the identification of Enterobacteriaceae. J Hyg 1981;87:287-97.

8 Blazevic DJ. Taxonomy, isolation, and identification of Serratia. p. 4-13. In:A von Graevenitz, SJ Rubin, eds. The Genus Serratia. Florida:CRC, 1980.

9 Mug PA. Comparison of Microbact-12E, API-20E and conventional media systems for the identification of Enterobacteriaceae. Aust J Med Technol 1979;1;:37-41.

Request for reprints to: Dr G L French, Department of Microbiology, The Chinese University of Hong Kong, The Prince of Wales Hospital, Shatin, New Territories, Hong Kong. 